Gut, 1967, 8, 178

\title{
Rectal stricture due to ischaemia following ruptured ectopic gestation
}

\author{
J. F. CURR \\ From the Department of Surgery, Wansbeck Group of Hospitals, Ashington, Northumberland
}

In a patient six days after an operation for ruptured ectopic gestation, symptoms of acute proctitis developed, followed by sloughing of the wall of the rectum and later by an intractable stricture of the rectum. It is believed that the cause of the rectal lesion was thrombosis of the superior rectal artery.

CASE REPORT

A woman of 40,6 feet in height and 16 stones in weight, had complained of severe abdominal pain for three days when she was admitted to hospital on 23 August 1952. She had been married less than a year but, menstruation having been erratic all her life, often occurring only twice a year, she did not know if she was pregnant. The diagnosis of ruptured ectopic gestation was obvious but she was in very poor general condition from severe blood loss and an immediate blood transfusion was given. At operation, a very large firm blood clot filled the pelvis and there was much fresh bleeding; the diagnosis was confirmed and the left tube and ovary were removed. She made an excellent recovery as far as her general condition and the abdominal operation were concerned.

On the sixth day symptoms of severe acute proctitis developed, with pain and complete incontinence. On the sixteenth day a large portion of necrotic rectal mucosa the size of the palm of the hand was extruded from the anus. Sigmoidoscopy was performed under a general anaesthetic, and it was seen that within four weeks a severe tubular rectal stricture had developed, with extensive ulceration, 2 in. long, and opposite the lower end of the sacrum; at first it would only admit a large urethral bougie. Complete incontinence persisted. A defunctioning left iliac colostomy was established. Sigmoidoscopy was repeated on each occasion during the next year when the stricture was dilated but it was not possible to pass an endoscope through the stricture. Ultimately the ulceration healed and extensive fibrosis developed at the site of the stricture, with fibrous bands stretching longitudinally into the healthy part of the rectum.

Eighteen months after the onset, an operation on the stricture was performed by the method described by Lockhart-Mummery and Lloyd-Davies (1935), the coccyx and last piece of sacrum being excised. There was dense perirectal fibrosis, with the rectum very firmly adherent to the bone at the site of the stricture, but it was possible to mobilize the rectum freely. A longitudinal incision was made on the posterior wall of the rectum through the stricture for $3 \mathrm{in}$. and the resulting opening in the rectum was sutured transversely. Rapid healing took place.

The ultimate result was excellent and the defunctioning colostomy was closed six months later, exactly two years after the onset. The progress of the patient was watched for seven more years, until 1961, and no relapse took place, perfect bowel function being maintained.

\section{DISCUSSION}

The importance of this case lies in the cause of the acute proctitis and rapid stricture formation. Accidental damage to the rectum by a scalding hot or corrosive enema, any attempt at abortion, or lymphogranuloma venereum was excluded.

There is every reason to believe that the cause was occlusion of the superior rectal artery and its branches. Due to severe blood loss, there was a sustained low blood pressure for many hours and, in addition, the massive firm blood clot filling the pelvis must have exerted considerable pressure on the vessels. In consequence, extensive thrombosis occurred in the artery and its branches, leading to tissue necrosis in the absence of an adequate collateral circulation.

No reference has been traced to ruptured ectopic gestation being complicated by acute proctitis and rectal stricture in several standard books on proctology and gynaecology and many surgical journals, and there has been but fleeting mention of vascular occlusion as a cause of these rectal conditions. Todd (1938) describes how excessive irradiation to the pelvis produces endarteritis, thrombosis, and occlusion of the superior rectal artery with subsequent stricture formation, but this is a slowly progressive process, not of an acute nature. Shearburn, Connell, and Hopkins (1955) describe a case of rectal ulceration due to ischaemic necrosis as a result of severe arteriosclerosis of the small rectal arteries, the process being gradual at first, but terminating fatally from perforation of an ulcer.

Shanahan and Steedman (1963) report a case of gross arteriosclerosis, associated with an aneurysm of the 
abdominal aorta, and complicated by sudden occlusion of the inferior mesenteric artery. Segments of necrotic intestinal mucosa were passed per rectum and a stricture of the rectum developed, along with extreme stenosis of the descending and pelvic colon. A defunctioning transverse colostomy had been life-saving at first, but the patient died four months later from small gut obstruction.

Marston, Pheils, Thomas, and Morson (1966) describe the condition of ischaemic colitis, divided into gangrenous, stricturing, and transient forms, and occurring from the same causes as myocardial infarction. Sixteen cases were studied, a stricture in the region of the splenic flexure developing in 12 cases, but in none was the rectum involved. Although the underlying vascular lesion was of a different nature, there is an obvious resemblance to the case now reported in that there was a sudden interference with the blood supply to a segment of gut. The mucous membrane being the most sensitive layer, the blood supply may be adequate to prevent complete destruction of the affected segment but is insufficient for the needs of the mucous membrane, with extensive sloughing of the latter as a result.

The mechanism suggested in the present case appears to be uncommon, judging by the paucity of references, but no doubt it has accounted for many strictures of uncertain aetiology.

REFERENCES

Lockhart-Mummery, J. P., and Lloyd-Davies, O. V. (1935). The operative treatment of fibrous stricture of the rectum, Brit. J. Surg., 23, 19-24.

Marston, A., Pheils, M. T., Thomas, M. L., and Morson, B. C. (1966.) Ischaemic colitis, Gut, 7, 1-15.

Shanahan, M. X., and Steedman, P. K. (1963). Inferior mesenteric artery occlusion, Brit. J. Surg., 50, 533-534.

Shearburn, E. W., Connell, J., and Hopkins, J. E. (1955). Rectal ulceration due to ischemic necrosis, Ann. Surg., 141, 563-566.

Todd, T. F. (1938). Rectal ulceration following irradiation treatment of carcinoma of the cervix uteri, Surg. Gynec. Obstet., 67, 617-631. 